\title{
Impressions of Euroson 2013 Meeting in Stuttgart, Germany
}

Just finishing my residency in radiology and becoming a fresh radiologist it was very exciting for me when I got the invitation to attend the EUROSON 2013 and the Dreiländertreffen in Stuttgart, Germany.

Before that attending many years in a row the ECR in Vienna and many local congresses in Slovenia and neighbouring countries, such as Slovenian-Hungarian-Croatian congress or Alpe-Adria meeting, this was my first time to attend such a specialized congress, dedicated specially to ultrasound and its use in different clinical settings and imaging algorithms.

With ,the use of ultrasound in different clinical settings' I mean the ever increasing use of ultrasound in the emergency room, at the patients bedside or even in the operating theatre. At the exhibition a poster titled "Intraoperative use of a wireless ultrasound device - a first clinical report" from Zenk J came to my attention, where the operating head and neck surgeon used the new wireless transducers in the operating room with great success. Portability and ease of use is a great benefit for the investigator, specially when using it in the emergency setting as a tool of POCUS (point of care ultrasound) or in the operating room, being an interventional radiologist or a surgeon.

During the congress I mostly attended refresher courses in vascular and pediatric ultrasound. There was one course called "Das unklare Bein" where besides the pathology of the veins and arteries also the pathology of the musculoskeletal system was discussed. A very experienced ortho- pedic surgeon Norbert Hien listed an extensive array of pathologies in the leg and showed us that every pain and complaint in the leg can be explained, you just have to know your line of work. In the same section Elmar Mertiny described the importance of a good clinical exam and D-dimer value before doing the ultrasound examination in searching for deep venous thrombosis. Truly you have to know what to search for and what to expect.

Another interesting session was about ultrasound of the lung titled "Bildgebung der Lunge“. At this point let me say that I was very happy to notice that my German professor from high school did a great job and I was able to follow the German lectures from Dreiländertreffen with no problems at all.

As expected imaging of the lung in case of pneumonia, a study presented by Angelica Riessig, can be very usefull or even straightforward, special caution was advised in the case of the so called fluidobronchogram, where a possible obstructing lesion could be the cause of pneumonia. At the contrast agents part of the session I was surprised that the presenter Christian Görg did not use much of CEUS (contrast enhanced ultrasound) in case of benign thoracic wall lesions but more so in case of lung consolidations, where the dual blood supply of the lung with great temporal resolution of the CEUS helps a great deal in differentiating different kinds of lesions.

In the pediatric sections I was specially interested in the role of CEUS in different clinical settings, where Doris Franke with

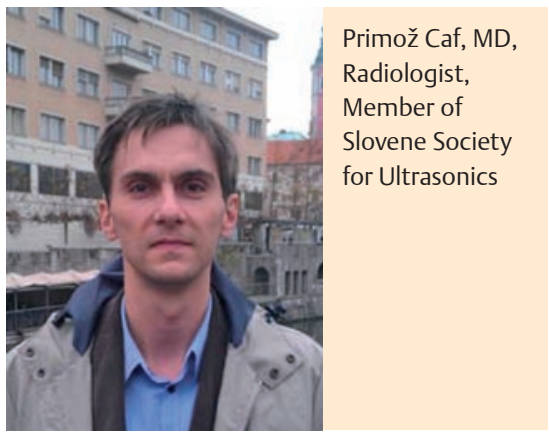

the lecture titled "CEUS in der Pädiatrie“ offered a great insight in what CEUS actually is, how it works and where we can use it, be it in the setting of trauma, tumors or inflammatory disease. At the same section Michael Riccabona lectured about the interventions in the child, presenting practical tips how to perform the procedures and which drugs to avoid, specially in renal interventions. At the end of the session Prof. Riccabona, a very respected friend of Slovene pediatric radiologists, opened the discussion of allergic reactions in the CEUS examinations, presenting few reported cases of allergic reactions in the use of CEUS and predicting that new reports of allergic reactions will arise, also in the off label use of CEUS in cistoureterography in children.

Indeed, the use of CEUS is expanding. Once being reserved only for the hepatic lesions, the last few years encouraging results arise also from the extrahepatic use of CEUS. In the section Update on current extrahepatic indications of CEUS I was 
very much surprised by a great deal of information one gets when one uses CEUS in solid lesions of the gallblader or when one wants to differentiate an adenocarcinoma from a neuroendocrine tumor in the pancreas, for example. Even further extrahepatic indications for the use of CEUS were presented at the Bracco symposium. The chairman Fabio Piscaglia made a great summary of all three lectures at the end and said that we should use CEUS whenever possible, be it in the assessment of kidney function, lymph nodes or in monitoring of liver interventions.

As far as the industry is concerned, I did not have much time to visit different manufacturers to test all the machines, but I took time to visit the Ultrasound learning centre. Performing doppler ultrasound for a few years by now, I had a lot of questions and doubts, so I attended the abdominal session "Focus on Doppler examination for portal hypertension and renal artery stenosis" with Theresa Fontanilla. She did a great job, answering all of my questions; I heard she also gave two wonderful lectures on doppler ultrasound and CEUS in liver transplantation and ARFI shear wave elastography as my colleagues reported.

Although in every imaging modality the specialists and investigators show great enthusiasm and never ending determination to get new insights into disease processes, I never felt such passion and even joy radiating from the specialists, presenting their insights into ultrasound as in this Ultraschall and Euroson 2013 meeting in Stuttgart, Germany.

The author received a sponsored registration for EUROSON 2013.

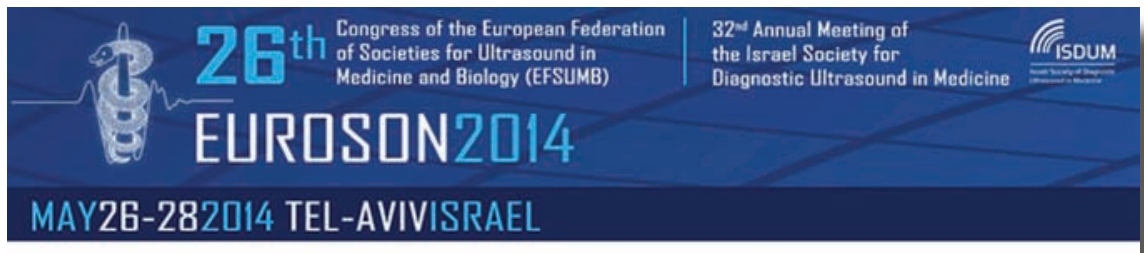

SEE YOU IN TEL-AVIV !

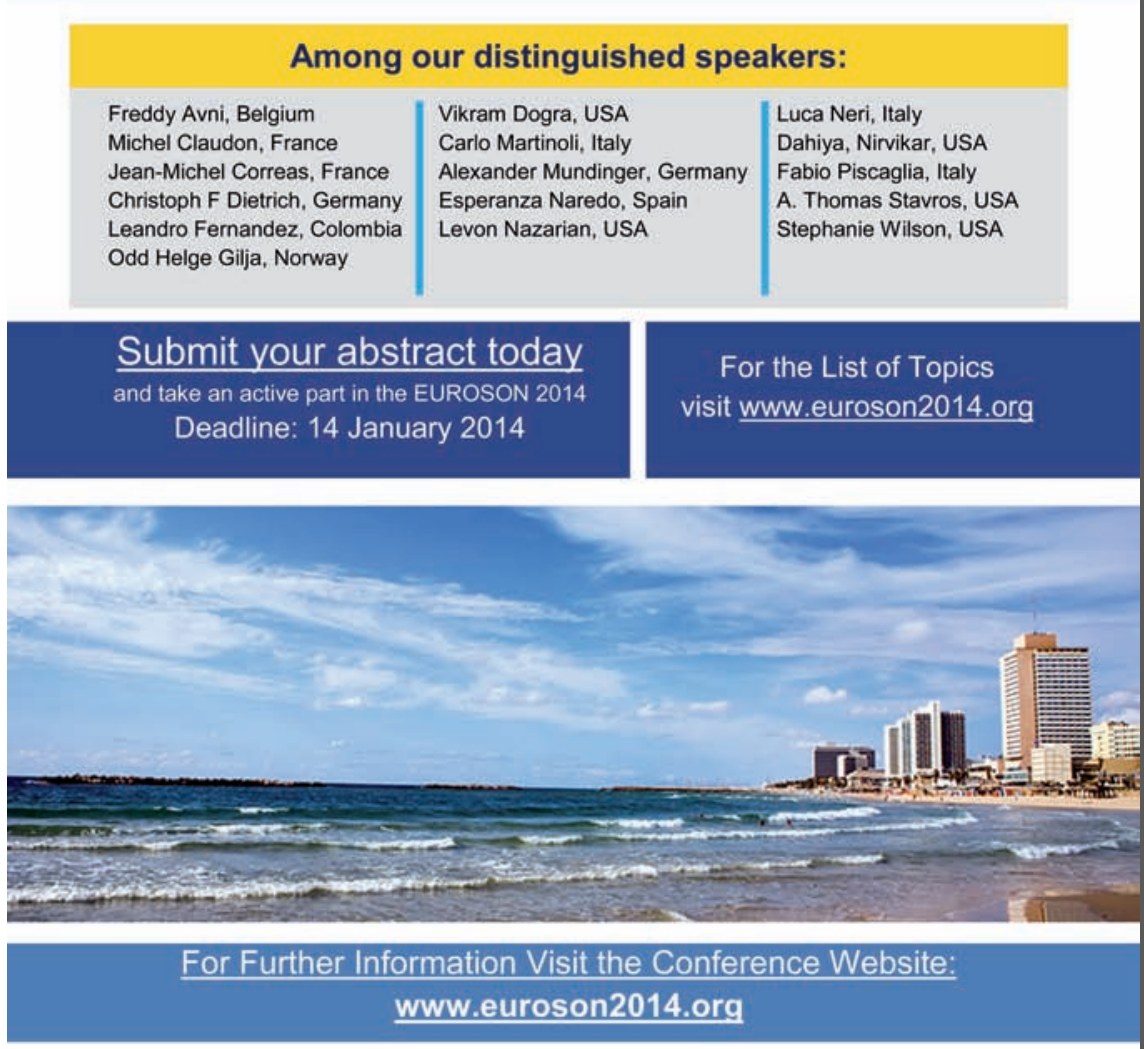

Conference Secretariat: Paragon Group

60 Medinat Hayehudim | 4676652 Herzliya | Israe

Telefax: +972-3-5767711 | Email: secretariat@euroson2014.ord

www.euroson2014,org 